\title{
TRABALHO FEMININO NO CERNE DO MERCADO DE TRABALHO ${ }^{1}$
}

\author{
Antonella Picchio ${ }^{2}$
}

RESUMO: Ao explicitar a dimensão capitalista do trabalho doméstico, este artigo propõe uma mudança importante na perspectiva analítica (e política) sobre as interações entre família e mercado de trabalho. A partir de uma análise estatística sobre a distribuição do tempo dedicado ao trabalho doméstico entre mulheres e homens na Itália e na França do final da década de 1980; de confrontar de forma veemente os pressupostos neoclássicos, especialmente a visão da família presente nas obras de Gary Becker; de questionar o potencial político das mulheres trabalhadoras apenas relacionado ao assalariamento, neutralizando o trabalho doméstico; e de abordar o Estado como a instituição que regula o arranjo entre o processo de acumulação e o processo de reprodução social, a autora argumenta que o trabalho doméstico seria o elo na relação entre a produção e a reprodução que sustenta o processo de acumulação de capital. Na sua análise do sistema capitalista, a exploração do trabalho para a reprodução e o controle das mulheres ganham centralidade, pois garantem a quantidade e qualidade do trabalho de produção necessário à acumulação. Sendo assim, é também a partir da questão da reprodução que se compreende a forma dos

\footnotetext{
${ }^{1}$ Este texto é o quinto capítulo do livro "Social Reprodution: the political economy of the labour Market", publicado pela Cambridge University Press, em 1992. O título original do quinto capítulo traduzido aqui é "Women's work at the core of the labour market". Tradução e revisão técnica de Maria Fernanda Cardoso de Melo (nanda.melo@gmail.com), Daniela Salomão Gorayeb (danisago@gmail.com), Juliana de Paula Filleti (juliana.filleti@facamp.com.br), Olivia Bullio Mattos (obulliomattos@sfc.edu) e Georgia Christ Sarris (georgia.sarris@facamp. com.br). Agradecemos à Antonella Picchio e à Cambridge University Press por permitirem a publicação deste capítulo. [Picchio, Antonella, "Social Reproduction: The Political Economy of the Labour Market", Chapter Five: "Women's work at the core of the labour market", (C) Cambridge University Press, 1992, reproduced with permission].

${ }^{2}$ Antonella Picchio é professora de Economia Política na Universidade de Modena e Reggio Emilia, na Itália.
} 
conflitos sociais, de classes e de gênero, o papel do Estado e a constituição das mulheres como sujeito político.

PALAVRAS-CHAVE: trabalho feminino; trabalho doméstico; produção capitalista e reprodução social; mercado de trabalho; movimento feminista.

\title{
WOMEN'S WORK AT THE CORE OF THE LABOUR MARKET
}

\begin{abstract}
By detailing the capitalist features of domestic work, this article proposes an important move in the analytical (and political) perspective on the interactions between family and the labor market. The study is focused on four fronts: i) a statistical analysis on the distribution of time between men and women dedicated to domestic work in Italy and France in the late 1980s; ii) a confrontation on the neoclassical assumptions in Gary Becker's perspectives on family; iii) a questioning of the political potential of working women that is only related to paid work, neutralizing domestic work and iv) an approach of the State as the institution responsible for regulating the relation between the process of accumulation and the process of social reproduction, arguing that domestic work is the link between production and reproduction that sustains the process of capital accumulation. In the author's study of a capitalist system, the exploitation of work for reproduction and the control of women are crucial, once they all but guarantee both the quantity and the quality of labor necessary to accumulation. It is also stemming from the matter of reproduction that one can understand social, class, and gender conflicts in all their forms, the role of the State, and the constitution of women as political subjects.
\end{abstract}

KEYWORDS: women's work, domestic work, capitalist mode of production and social reproduction, labor market, feminist movement.

\section{O TRABALHO REPRODUTIVO}

No mercado de trabalho feminino algumas características se mantêm surpreendentemente constantes: (a) o número substancial de mulheres sem trabalho remunerado; (b) a quantidade de trabalho doméstico ${ }^{3}$ feito por mulheres assalariadas; (c) segregação do trabalho; (d) grande proporção de mulheres em situação de pobreza.

\footnotetext{
${ }^{3}$ NT: Em quase todo o artigo, a autora se refere a trabalho doméstico (housework) como aquele que é realizado no âmbito doméstico e não é remunerado. A mesma observação vale para "trabalhadoras domésticas" (bouseworkers).
}

Temáticas, Campinas, 26, (52): 69-104, ago./dez. 2018 
A persistência desses fatos, a despeito das mudanças radicais nas estruturas sociais e produtivas, apresenta uma nova perspectiva para a relação entre produção e reprodução. Por exemplo, enquanto os dados das taxas de atividade ${ }^{4}$ mostram mudanças de nível e de composição (como o grande aumento de mulheres casadas e mulheres com crianças), ainda se observa uma concentração muito elevada nos empregos menos qualificados ou serviços domésticos. A porcentagem de mulheres sem trabalho remunerado continua similar ao cenário do final do século XIX (tabela 1), embora tenham havido importantes mudanças no controle da natalidade (levando a uma redução das taxas de fertilidade), nas estruturas familiares e nos níveis educacionais - todos fatores determinantes para a entrada de mulheres no mercado de trabalho (Hartmann \& Reskin, 1986) ${ }^{5}$.

Para entender tudo isso precisamos olhar para o lado sombrio e escondido do trabalho feminino e do trabalho doméstico. Se começarmos com o mercado de trabalho feminino, nunca conseguiremos apresentar a magnitude e a importância dos problemas envolvidos. Uma razão para essa limitação está no fato de o trabalho doméstico ser reprimido nos modelos analíticos do mercado de trabalho, por tenderem a marginalizar e a ocultar todo o processo de reprodução. Neste capítulo, portanto, definirei o trabalho doméstico e tentarei quantificá-lo em sua dimensão atual, usando dados estatísticos.

Quando a relação entre a produção e a reprodução desaparece da análise do contexto econômico, o trabalho concreto de reprodução fica camuflado e as trabalhadoras domésticas se tornam socialmente invisíveis, mesmo que representem uma grande parcela da população de trabalhadores. Mais precisamente, não é o trabalho doméstico ou as trabalhadoras domésticas que ficam escondidas, mas sim a relação capitalista entre a produção e a reprodução. E é assim que o problema central de qualquer sistema econômico se torna um problema restrito e marginal das mulheres.

\footnotetext{
${ }^{4}$ As taxas de atividade são definidas como a porcentagem de mulheres no mercado de trabalho (empregadas ou desempregadas) comparadas com o total da população em idade ativa (PIA). ${ }^{5} \mathrm{O}$ mesmo aparece em Hakim (1981).
} 
TABELA 1 - População Economicamente Ativa* e desemprego, 1987

\begin{tabular}{|c|c|c|c|c|c|}
\hline Países & Eur12 & $\begin{array}{l}\text { Alemanha - } \\
\text { Ocidental }\end{array}$ & França & Itália & Reino Unido \\
\hline Taxas de atividades & & & & & \\
\hline Feminina & 33,3 & 34,7 & 35,9 & 29,4 & 39,4 \\
\hline Masculina & 55,2 & 58,5 & 51,0 & 55,2 & 59,1 \\
\hline Meio período** & & & & & \\
\hline Feminina & 28,6 & 29,0 & 22,5 & 8,7 & 44,5 \\
\hline Masculina & 3,4 & 1,3 & 3,3 & 2,6 & 5,0 \\
\hline $\begin{array}{c}\text { Taxas de desem-prego } \\
\text { (média anual) }\end{array}$ & & & & & 10,1 \\
\hline Feminina & 13,2 & 8,0 & 13,5 & 17,3 & 11,0 \\
\hline Masculina & 8,9 & 5,3 & 8,3 & 7,4 & \\
\hline
\end{tabular}

* A População Economicamente Ativa compreende todas as pessoas empregadas e desempregadas.

** Porcentagem de empregos para meio período no total do emprego. Fonte: EUROSTAT, 1989, p. 99-182, 223.

É verdade que as definições recentes de trabalho foram ampliadas para incluir o trabalho reprodutivo não remunerado (Gershuny \& Jones, 1986; R.L. Pahl, 1984); e, em estudos empíricos sobre o uso do tempo, o trabalho doméstico e o trabalho remunerado são somados para calcular a jornada de trabalho. Este é um passo necessário em direção à equidade, porém não ajuda em termos de clareza: o importante no caso do trabalho feminino não é a ampliação do significado do termo trabalho, mas sim especificar a relação entre produção-reprodução.

A natureza dessa relação se torna evidente se utilizarmos a abordagem do excedente para olharmos o lucro. O trabalho doméstico é a produção do trabalho como uma mercadoria, enquanto o trabalho remunerado é a troca do trabalho. Para ocorrer a troca, o trabalho precisa ser produzido; e para ser utilizado na produção de outras mercadorias, o trabalho precisa ser produzido e trocado. E isto não ocorre meramente por uma questão cronológica, é uma relação funcional entre processos. 
Enquanto os salários são considerados custos de produção, o trabalho doméstico não pago é uma dedução dos custos. É desnecessário dizer que o trabalho doméstico possui seus próprios custos (tal como a sobrevivência da trabalhadora doméstica), mas essa relação é feita de forma a garantir um elevado excedente. Essa relação não é óbvia diretamente, pois o trabalho não é vendido por capitalistas: o excedente é apropriado pelos capitalistas não pela venda do trabalho, mas por sua compra ${ }^{6}$.

Foi por isso que Adam Smith reconheceu, como vimos no primeiro capítulo $^{7}$, que um trabalhador bem alimentado e bem vestido custa menos ao seu empregador do que um escravo mal alimentado e malvestido. Ele explica o paradoxo apontando o fato de que a administração da reprodução dos trabalhadores passou a ser uma responsabilidade do empregador, e não mais do próprio trabalhador. O paradoxo do valor-trabalho - isto é, o fato de que quanto mais trabalho for incorporado na sua reprodução, menor será o custo para o empregador - pode ser explicado apenas no contexto da separação do processo de produção e de reprodução, com a distinção capitalista entre trabalho remunerado e trabalho não remunerado, e com a subordinação social da reprodução para as necessidades da acumulação

\footnotetext{
${ }^{6}$ Nos anos 1970 houve um intenso debate sobre o trabalho doméstico originado no contexto militante feminista (Dalla Costa \& James, 1972; Federici, 1976) e que foi transformado em um debate mais marxista ortodoxo e acadêmico (Molineaux, 1979; Himmelweit \& Mohun, 1977; Folbre, 1982). É possível encontrar uma coleção dos textos que nortearam o debate do trabalho doméstico em Malos (1982), com atenção especial para Federici (1976).

Enquanto a discussão política foi conduzida dentro - e contra - a Campanha de Salários para o Trabalho Doméstico, o debate acadêmico focou, principalmente, na aplicação da teoria marxista de exploração e do valor-trabalho. Logo o debate se formalizou com interesses voltados mais aos aspectos quantitativos do que aos aspectos inovadores de uma perspectiva política feminista.

N.T.: A Campanha de Salários para o Trabalho Doméstico - ou The International Wages for Housework Campaign - foi um movimento feminista social surgido nos anos 1970, na Itália, sendo suas principais expoentes: Selma James, Brigitte Galtier, Mariarosa Dalla Costa e Silvia Federici. Veja: https://freedomarchives.org/Documents/Finder/DOC500_scans/500.020. Wages.for.Housework.pdf, e James, Selma. Is transformation possible? They say we can't. We say we must. Off Our Backs, v. 38, n. 1 (2008), pp. 40-43, para maiores detalhes das reinvindicações do movimento.

${ }^{7}$ N.T.: A autora se refere ao capítulo 1 do livro desta tradução, "Social Reprodution: the political economy of the labour Market".
} 
de capital. O que é paradoxal para a teoria do valor se torna trágico para as mulheres, visto que as contradições e os conflitos do sistema se materializam em suas vidas pessoais.

Sociólogos se concentram, tanto no nível internacional quanto no local, no uso do tempo. Uma quantidade considerável de informações emerge dos estudos empíricos bastante difusos das complexas interações sociais entre as famílias e o mercado de trabalho, e entre o trabalho doméstico e o trabalho assalariado (Gershuny \& Jones, 1986; R.L. Pahl, 1984; Roy, 1989; Saraceno, 1987). O que precisamos agora é uma estrutura analítica para a nova consciência, só para ter certeza de fazer pleno uso dos novos dados. Essa necessidade é notada, por exemplo, por Gershuny e Jones que estão fazendo um trabalho valioso coletando arquivos do uso do tempo na Fundação Europeia para a Melhoria da vida e das Condições de trabalho, baseada em Dublin:

Este é um grande conjunto de trabalhos empíricos e, considerando a natureza fundamental e compreensiva dos dados que produz, deveria ter tido um efeito substancial nas ciências sociais. De fato, seu impacto não foi impressionante. Salvo algumas honrosas exceções, as publicações que surgem como resultado da pesquisa da gestão do tempo são levemente descritivas e teoricamente desinformadas e não informativas. Existem duas razões conectadas para isso: as complicações práticas da análise da gestão do tempo - e a ausência quase completa de uma teoria apropriada (...). Ainda não temos teorias adequadas sobre a determinação dos padrões de uso do tempo; os modelos elegantes e cada vez mais sofisticados produzidos pelos economistas, os quais buscam explicar as diferenças para dados de corte e mudanças históricas nos padrões de uso do tempo por diferenças salariais (exemplo Becker 1965, Gronau 1977), enquanto são consistentes internamente, carregam pouca relação com os padrões intrínsecos de comportamento exibidos pelos dados (Gershuny \& Jones, 1986, p. 3-4). 
O trabalho doméstico não é meramente uma combinação de tarefas necessárias para a reprodução diária das famílias e para a vida física ou psicológica de seus membros. Esse restaura a relação entre produção e reprodução que faz sentido do ponto de vista das pessoas envolvidas. É esperado que, dentro da família, com as mulheres e seu trabalho doméstico, a relação alienada que estrutura o sistema de produção e o sistema social será revertida e seus conflitos absorvidos. O trabalho doméstico serve ao bem-estar das pessoas, enquanto a produção de mercadorias é orientada para a acumulação do capital. Acumulação usa pessoas como mercadorias, e a tarefa do trabalho doméstico é produzir e restaurá-las como pessoas dentro dos limites da reprodução delas como mercadorias. É isto que torna este trabalho interminável, embora tenham ocorrido muitas mudanças nas famílias, na tecnologia e na estrutura ocupacional do mercado de trabalho assalariado. A família, entretanto, define e compõe funções como um alternador: no mundo lá de fora, a direção da energia vai da reprodução de pessoas para a produção de mercadorias (acumulação de capital), enquanto na família esta direção deve ser revertida - ao menos aparentemente - em favor de um processo mais humano pelo qual a reprodução de pessoas é o objetivo final e a produção de mercadorias é apenas o meio.

A família precisa oferecer um espaço, físico e psicológico, no qual os indivíduos se sintam o centro das atenções, o objetivo final da atividade social. Quanto mais alienada for a relação entre as pessoas e o sistema de produção, mais pesado e difícil se torna o trabalho doméstico. E o trabalho doméstico é ainda mais difícil quanto mais desigual for a sua distribuição dentro da família entre os homens e as mulheres (Maurin, 1989; Saraceno, 1987).

Dentro do trabalho reprodutivo realizado pelas mulheres nas famílias, é impossível distinguir entre as tarefas materiais e o cuidado psicológico das pessoas (Finch \& Groves, 1983). O amor da mulher na família é expresso e exigido em termos de trabalho. A diferença de gênero reflete na enorme quantidade de energia que as mulheres derramam nos demais, para que eles se sintam como seres humanos em um sistema que os trata como mercadorias (seja em uso, para uso futuro ou fora de uso). Historicamente o trabalho material de reprodução e de reafirmação da 
identidade pessoal - incluindo os homens adultos - tem sido delegado às mulheres. Isso significa que as mulheres precisam compensar os serviços públicos inadequados e os efeitos destrutivos do mercado de trabalho. Quanto mais esses efeitos são disfarçados, mais a família se torna um lugar onde as tensões e inseguranças de todos os membros são descarregadas.

\section{ALGUMAS EVIDÊNCIAS EMPÍRICAS}

A diferença significativa entre o trabalho feito pelas mulheres e pelos homens na família, a persistência de quantidades enormes de trabalho doméstico, a estreita dependência dos comportamentos dos homens e das mulheres nas famílias a padrões históricos de normas sociais impostas tudo isso é muito conhecido da experiência diária, e parece desnecessário insistir mais nesses pontos. Mas, na verdade, a transposição da experiência direta da esfera de conhecimento comum para a pesquisa acadêmica envolve mudanças de perspectiva e de sujeito e objetos de pesquisa:

Todo saber (wissen ${ }^{8}$ ) tem seu próprio estilo de pensamento com suas tradição e educação específicas. Da quantidade quase infinita de possibilidades, todo caminho para o saber seleciona questões diferentes, conectando-as de acordo com diferentes regras e a diferentes propósitos (Fleck, 1986, p.49) $)^{9}$.

Nesta transposição entre o conhecimento comum e o científico, importantes aspectos da experiência comum frequentemente se tornam menos visíveis e aparentam ser de menor importância. Essa perda de foco não é resultante apenas do processo de abstração: ela também reflete as relações de poder entre os sujeitos sociais, na sociedade e na profissão científica. No caso do trabalho doméstico, o problema não está relacionado apenas ao fato que a mulher tem menos poder nas instituições sociais, e

\footnotetext{
${ }^{8}$ N.T.: wissen, termo em alemão que significa saber.

${ }^{9}$ Para maiores detalhes sobre o tema dentro das comunidades científicas veja Jardine (1986, p. 120-33).
}

Temáticas, Campinas, 26, (52): 69-104, ago./dez. 2018 
especificamente na comunidade científica, mas ao fato de que a análise econômica predominante, em geral, esconde o processo de reprodução social do trabalho.

Estatísticas disponíveis ajudam a iluminar as dimensões dessa questão. Vamos começar com os casos da Itália e da França, e depois continuaremos com comparações de algumas tendências históricas em diferentes países. A tabela 2 apresenta uma ideia quantitativa da distribuição desigual do trabalho doméstico entre homens e mulheres na Itália. Uma comparação do quadro geral mostra que a média total do número de horas por semana é de 5,5 para os homens e de 36,3 para as mulheres. Mas, o que é mais interessante é que os homens que moram com mulheres, formando um casal, fazem apenas a metade do trabalho doméstico feito por homens que moram sozinhos; a outra metade é transferida para a mulher. $\mathrm{O}$ fato da mulher ter mais horas de trabalho doméstico do que o homem quando eles moram sozinhos, devido à educação e falta de dinheiro para os serviços de mercado, não explica o fato de trabalharem mais do que os homens quando eles estão morando juntos. Dessa maneira, mulheres que moram junto fazem mais trabalho doméstico do que mulheres sozinhas, e essa diferença aumenta conforme aumenta o tamanho da família. Por exemplo, o nascimento do primeiro filho no grupo de idade entre 25-44 gera um acréscimo de cerca de 8 horas no trabalho doméstico por semana da mulher e uma leve queda no trabalho do homem. Isso derruba o mito de que as crianças são a única causa da jornada excessiva de trabalho doméstico feminino. Outra surpresa interessante na tabela é o fato de que quando o número de crianças aumenta, a quantidade de trabalho doméstico feita pelo homem, com idade entre 25 e 45 anos, realmente diminui de 9,5 para 3,8 horas, enquanto a da mulher passa de 21,6 para 45,7 horas. 
TABELA 2 - Itália, média do número de horas semanais do trabalho doméstico, de acordo com o sexo, idade e tamanho da família

\begin{tabular}{|l|l|l|l|l|l|l|l|}
\hline Idade & 1 & 2 & 3 & 4 & 5 & $6+$ & Total \\
\hline \multicolumn{7}{|l|}{} \\
\hline HOMENS & 8,3 & 4,5 & 3,0 & 2,7 & 2,8 & 2,7 & 2,9 \\
\hline $25-44$ & 9,5 & 5,8 & 5,6 & 5,2 & 5,1 & 3,8 & 5,4 \\
\hline $45-64$ & 15,1 & 7,8 & 6,3 & 3,3 & 5,2 & 5,4 & 6,3 \\
\hline 65+ & 17,1 & 8,5 & 7,7 & 6,3 & 8,0 & 5,5 & 8,7 \\
\hline TOTAL & 14,1 & 7,4 & 5,6 & 4,6 & 4,4 & 3,9 & 5,5 \\
\hline \multicolumn{7}{|l|}{} & MULHERES \\
\hline 14-24 & 24,4 & 29,1 & 26,0 & 16,9 & 15,6 & 18,1 & 19,5 \\
\hline 25-44 & 21,6 & 30,9 & 38,6 & 44,9 & 45,8 & 45,7 & 41,8 \\
\hline 45-64 & 32,3 & 41,7 & 45,8 & 48,0 & 47,8 & 46,9 & 44,6 \\
\hline 65+ & 29,2 & 35,7 & 33,1 & 25,2 & 25,2 & 26,0 & 31,3 \\
\hline TOTAL & 29,5 & 38,3 & 37,9 & 37,9 & 33,4 & 36,3 \\
\hline
\end{tabular}

Fonte: ISTAT (1989, 1985, p. 73).

Entre as mulheres vivendo com parceiros, sem filhos, o número de donas de casa não é muito menor do que o de mulheres empregadas: evidentemente o mero fato de formar um casal afeta fortemente as suas taxas de emprego. Isto fortalece a visão de que há uma parcela central do trabalho doméstico sem qualquer correlação com o número de filhos e que para 36,6\% das mulheres que moram junto, a presença de um companheiro age como impedimento para a entrada no mercado de trabalho assalariado. A proporção de donas de casa cresce com o número de crianças até que atinge 65\% (Fadiga Zanatta, 1988, p. 291). Então, na Itália, ainda hoje, uma porcentagem muito significativa de mulheres de todas as idades ainda possui o trabalho doméstico como sua única ocupação, embora isso não signifique que as mesmas mulheres sejam permanentemente donas de casa.

O trabalho doméstico, claro, não é feito pelas donas de casa sozinhas, contudo em muitos casos sim. Mas também é realizado pelas mulheres com empregos: de 27,2 horas por semana para mulheres sem filhos até 
34,5 horas por semana para mulheres com 3 crianças (tabela 3). A mesma tabela também mostra que a 'dupla jornada' é um fenômeno puramente feminino. As pouquíssimas horas de trabalho doméstico realizadas pelos homens não aumentam nem com o acréscimo do número de filhos ou em resposta aos trabalhos assalariados de suas esposas.

TABELA 3 - Itália, número médio semanal de horas de trabalho doméstico realizado por casais, de acordo com o número de filhos e emprego feminino

\begin{tabular}{|l|c|c|c|c|c|}
\hline \multirow{2}{*}{ Número de filhos } & \multicolumn{2}{|l|}{$\begin{array}{l}\text { Unidade familiar com mu- } \\
\text { lher empregada }\end{array}$} & \multicolumn{2}{l|}{$\begin{array}{l}\text { Unidade familiar sem mu- } \\
\text { lher empregada }\end{array}$} & \multirow{2}{*}{ Total } \\
\cline { 2 - 5 } & Feminino & Masculino & Feminino & Masculino & \\
\hline Sem crianças & 27,2 & 6,4 & 43,1 & 7,6 & 23,2 \\
\hline 1 filho & 31,7 & 6,6 & 52,1 & 6,1 & 25,2 \\
\hline 2 filhos & 33,4 & 6,2 & 56,0 & 5,2 & 27,0 \\
\hline 3 filhos & 34,5 & 6,0 & 57,1 & 5,0 & 28,0 \\
\hline 4 filhos & 32,1 & 4,8 & 57,6 & 5,3 & 28,1 \\
\hline 5 ou mais filhos & 36,1 & 5,9 & 55,5 & 4,2 & 28,6 \\
\hline TOTAL & 31,7 & 6,3 & 51,5 & 6,1 & 25,7 \\
\hline
\end{tabular}

Fonte: ISTAT (1989, 1985, p. 74).

O caso da Itália é menos provinciano do que se poderia esperar. A França, por exemplo, apresenta o mesmo tipo de padrão que aparece em alguns estudos muito interessantes sobre a alocação do tempo para o trabalho e atividades de vida. A tabela 4 confirma a distribuição do tempo de trabalho entre os sexos (desagregados pelo número de filhos), os quais já foram apresentados para a Itália na tabela 3. Se adicionarmos a assim chamada 'jornada total' ${ }^{10}$, (i.e., tempos de trabalho pagos e não pagos) vemos que entre as várias seções da população trabalhadora, é a mulher empregada que suporta a carga mais pesada do trabalho (com média superior a 10 horas diárias). Depois vem o homem empregado, e então a mulher sem trabalho remunerado - quem, contudo, trabalha tantas horas

${ }^{10}$ Em inglês: constrained times. 
quanto um homem se ela tiver três filhos. Na França também, o trabalho doméstico dos homens diminui conforme o número de filhos aumenta, mesmo em casos em que as mulheres possuem trabalho remunerado.

Tendo esboçado um retrato para a Itália e a França indicando a quantidade de trabalho doméstico e as diferenças evidentes na distribuição entre os sexos, podemos agora tentar ver se as horas de trabalho doméstico tendem historicamente a decrescer, se o fenômeno é limitado geograficamente e se as diferenças entre os gêneros estão diminuindo. Temos alguns dados disponíveis para os EUA e uma comparação, ao longo do tempo, entre diferentes países.

A tendência do trabalho doméstico nos EUA é efetivamente ilustrada pelos dados publicados por Vaneck $(1980)^{11}$. Os resultados servem para relativizar algumas visões generalizadas e otimistas sobre a relação entre o crescimento econômico e a redução do trabalho doméstico. Comprovase que, no período entre 1926 e 1964, embora tenham havido enormes mudanças nos tipos de casas, bens de consumo (duráveis ou não duráveis) e estruturas familiares, o montante de trabalho doméstico não diminuiu e ainda aumentou: para as donas de casa subiu de 51 para 56 horas por semana. Numa situação urbana com água corrente, melhores serviços de saúde e utensílios domésticos, a redução no tempo usado para o preparo da comida foi mais que compensado pelo aumento do tempo dedicado aos cuidados com a casa, às compras, ao lidar com a burocracia e aos cuidados com as crianças (Vaneck, 1980, p. 82-7).

${ }^{11}$ Os dados foram coletados em uma base de pesquisa financiada, em 1925, pelo Governo Federal. As mulheres foram convidadas a elaborar orçamentos de tempo nas bases dos guias fornecidos pelo US Bureau of Home Economics (Serviço de Economia Doméstica dos EUA). A mesma metodologia foi aplicada em estudos nos anos 1930s, 1940s, 1950s e 1960s (Vaneck, 1980, pp.82-3).

Temáticas, Campinas, 26, (52): 69-104, ago./dez. 2018 
TABELA 4 - França, uso do tempo de acordo com o número de filhos e ocupação da mulher, 1981.

\begin{tabular}{|c|c|c|c|c|c|c|}
\hline \multirow{3}{*}{ Tempo gasto em: } & \multicolumn{6}{|c|}{ Homens com: } \\
\hline & \multicolumn{3}{|c|}{ Esposas empregadas } & \multicolumn{3}{|c|}{ Donas de casa } \\
\hline & 1 filho & 2 filhos & $3 \mathrm{ou}+$ & 1 filho & 2 filhos & $3 \mathrm{ou}+$ \\
\hline Trabalho pago & $6 h 30$ & $6 \mathrm{~h} 40$ & $7 \mathrm{~h} 25$ & $6 \mathrm{~h} 50$ & $6 \mathrm{~h} 50$ & $6 h 35$ \\
\hline Trabalho doméstico & $2 \mathrm{~h} 10$ & $2 \mathrm{~h} 05$ & $1 \mathrm{~h} 40$ & $1 \mathrm{~h} 35$ & $1 \mathrm{~h} 40$ & $1 \mathrm{~h} 45$ \\
\hline Jornada Total & $8 \mathrm{~h} 40$ & $8 \mathrm{~h} 45$ & $9 \mathrm{~h} 05$ & 8 h25 & $8 \mathrm{~h} 30$ & $8 \mathrm{~h} 20$ \\
\hline Necessidades físicas & $11 \mathrm{~h}$ & $11 \mathrm{~h}$ & $10 \mathrm{~h} 55$ & $11 \mathrm{~h}$ & $11 \mathrm{~h}$ & $11 \mathrm{~h} 30$ \\
\hline$\overline{\text { Lazer }}$ & $4 \mathrm{~h} 20$ & $4 \mathrm{~h} 15$ & $4 \mathrm{~h}$ & $4 \mathrm{~h} 45$ & $4 \mathrm{~h} 30$ & $4 \mathrm{~h} 10$ \\
\hline \multirow{3}{*}{ Tempo gasto em: } & \multicolumn{6}{|c|}{ Mulheres: } \\
\hline & \multicolumn{3}{|c|}{ Empregadas } & \multicolumn{3}{|c|}{ Donas de casa } \\
\hline & 1 filho & 2 filhos & $3 \mathrm{ou}+$ & 1 filho & 2 filhos & $3 \mathrm{ou}+$ \\
\hline Trabalho pago & $5 \mathrm{~h} 30$ & $4 \mathrm{~h} 40$ & $4 \mathrm{~h} 40$ & - & - & - \\
\hline Trabalho doméstico & $4 \mathrm{~h} 35$ & 5 h15 & $5 \mathrm{~h} 45$ & $7 \mathrm{~h} 30$ & $8 \mathrm{~h} 10$ & $9 \mathrm{~h}$ \\
\hline Jornada Total & $10 \mathrm{~h} 05$ & $9 \mathrm{~h} 55$ & $10 \mathrm{~h} 25$ & $7 \mathrm{~h} 30$ & $8 \mathrm{~h} 10$ & $9 \mathrm{~h}$ \\
\hline Necessidades físicas & $10 \mathrm{~h} 55$ & $11 \mathrm{~h}$ & $10 \mathrm{~h} 40$ & $11 \mathrm{~h} 30$ & $11 \mathrm{~h} 15$ & $11 \mathrm{~h} 15$ \\
\hline Lazer & $3 \mathrm{~h}$ & $3 \mathrm{~h} 05$ & $2 \mathrm{~h} 55$ & $5 \mathrm{~h}$ & $4 h 35$ & $3 \mathrm{~h} 45$ \\
\hline
\end{tabular}

Fonte: Roy (1982, p. 60).

Szalai (1975) compara as horas de trabalho das donas de casa com as das mulheres que possuem trabalho remunerado. Nas mais diferentes instituições ou contextos produtivos, os resultados mostram que se o trabalho doméstico é dividido de acordo com tarefas, tanto para mulheres empregadas ou para as donas de casa, o montante total de trabalho não diminui com o tempo e as diferenças tendem a aumentar. $\mathrm{O}$ total diário para as donas de casa é de 6,1 horas em 1926 e 6,2 horas em 1969, enquanto para as mulheres empregadas são, respectivamente, 3,8 em 1952 e 4,5 em 1969 (Szalai, 1975, p. 393) ${ }^{12}$.

${ }^{12}$ Os cuidados com os filhos não estão incluídos entre os deveres e, consequentemente, o cenário representa apenas parte do trabalho doméstico total. 


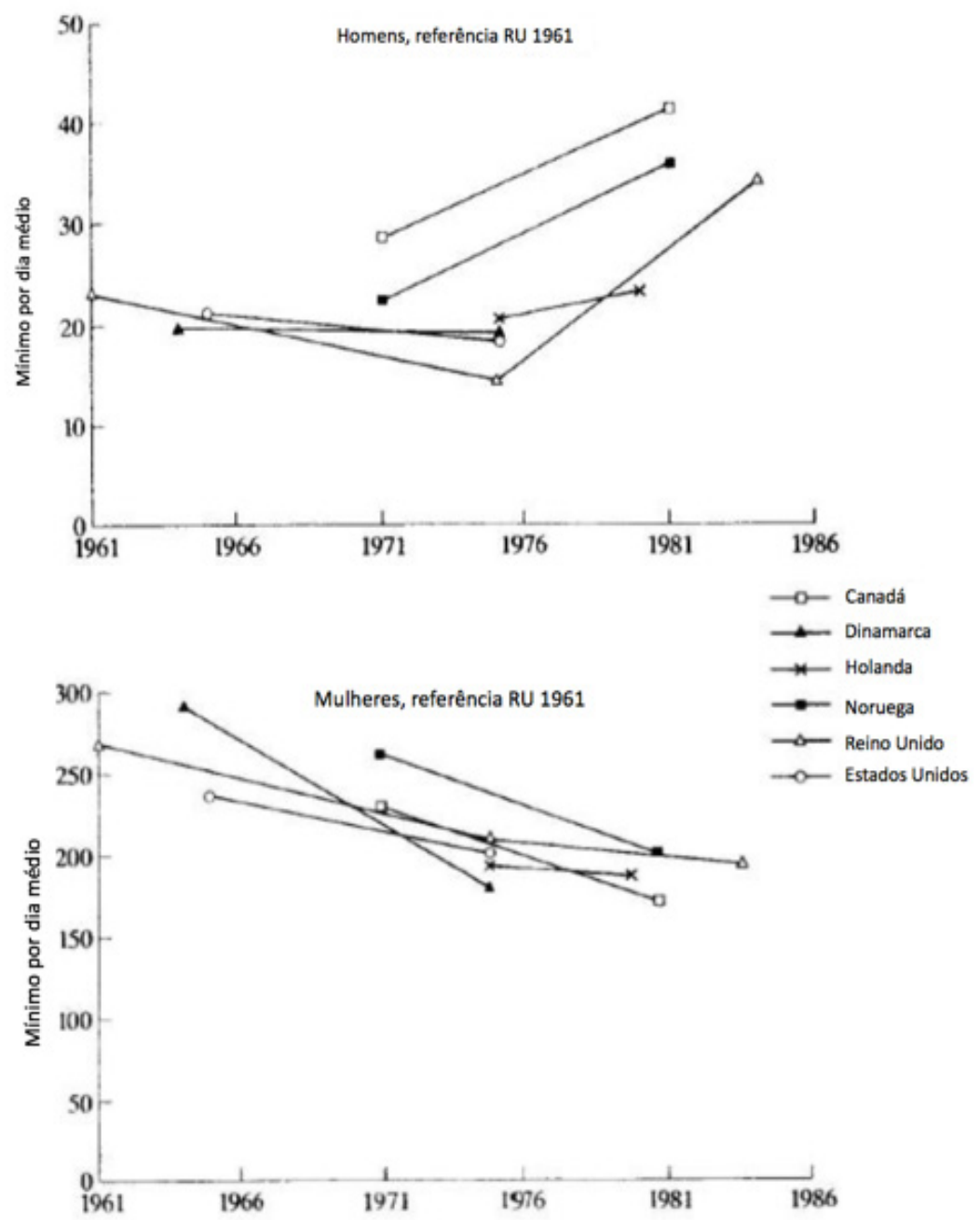

Fonte: Gershuny e Jones (1982, p. 60).

Temáticas, Campinas, 26, (52): 69-104, ago./dez. 2018 
Robinson e Converse (1972) depois de padronizar as amostras - eliminando, por exemplo, diferenças devido ao fato de as mulheres sem emprego terem mais crianças - concluíram que a disparidade entre mulheres empregadas e donas de casa não surge de uso maior da tecnologia ou serviços externos, ou pelo maior apoio dado pelos maridos das mulheres empregadas (Vaneck, 1980, p. 87-8). Os padrões de cuidados com a casa e com os filhos se mostram similares para as duas categorias; consequentemente, as diferenças são, aparentemente, devido a uma organização mais eficiente do trabalho. $\mathrm{Na}$ realidade, Vaneck endossa a opinião de Szalai de que as donas de casa trabalham tanto quanto os homens para sentirem (e então poderem mostrar) que elas ganham seu sustento. Esta explicação ideológica não explica por que mulheres assalariadas trabalham tantas horas nos serviços domésticos também.

As diferenças marcadas entre os trabalhos dos homens e das mulheres emergem também dos dados apresentados por Gershuny e Jones (1986). Esses dados nos permitem fazer algumas comparações entre os diferentes países - os Estados Unidos, o Reino Unido, a Dinamarca, o Canadá, a Holanda e a Noruega - para o período de 1961-85. Assim como nos casos para a Itália e a França, há evidências que a estrutura familiar, enquanto influencia fortemente os trabalhos das mulheres assalariadas ou não assalariadas, deixa o dos homens praticamente inalterados (Gershuny \& Jones, 1986, p. 30) ${ }^{13}$.

As diferenças nas jornadas de trabalho são tais que os gráficos que as representam normalmente utilizam escalas diferentes para os homens e para as mulheres. As horas de trabalho dos homens são, em geral, medidas em segmentos de 10 em 10 minutos, enquanto para as mulheres os segmentos mudam para a ordem de centenas (gráfico 1). Não são levantadas questões sobre o tamanho ou a persistência da diferença

\footnotetext{
${ }^{13}$ No estudo de Gershuny e Jones as comparações entre homens e mulheres são feitas na base: a) trabalho formal, i.e. trabalho pago incluindo trabalho em casa, formação para o segundo trabalho e viagem para ou do trabalho; b) trabalho doméstico, o qual inclui cozinhar e lavar, tarefas domésticas, trabalhos avulsos, jardinagem, compras, cuidados com as crianças e viagens domésticas; c) cuidados pessoais, incluindo vestir, serviços pessoais, comidas e lanches, dormir e descansar (Gershuny \& Jones, 1986, pp. 17-18).
} 
de gênero, mas os dados mostram uma redução no trabalho doméstico realizado pelas mulheres e um ligeiro aumento no realizado pelos homens. A redução do trabalho doméstico das mulheres se deve ao aumento do número de mulheres com empregos remunerados. Como no caso anterior, as diferenças de tempo gastos entre as mulheres que trabalham fora e as donas de casa, principalmente, refletem ritmos diferentes de trabalho, mais do que responsabilidades ou obrigações diferentes. Todas as mulheres precisam fazer, e geralmente fazem, os mesmos trabalhos; mas elas se organizam de formas diferentes. $\mathrm{Na}$ realidade, uma marcante diferença ideológica seria muito improvável dado que quase todas as mulheres têm empregos remunerados em vários momentos de suas vidas; são poucas as mulheres que ficam exclusivamente como 'donas de casa'. As diferenças de hábitos e normas sociais são principalmente conectadas às diferenças geracionais, de classes ou de níveis educacionais. Para os homens, contudo, o aumento parece ser atribuído a uma mudança nas atitudes sociais durante os 1970 (Gershuny \& Jones, 1986, p. 77).

No caso do cuidado com as crianças, as diferenças absolutas entre homens e mulheres são muito evidentes e mais uma vez isto é comum a todos os países (Gershuny \& Jones, 1986, p.55). O tempo dedicado às compras geralmente aumenta as diferenças entre homens e mulheres (p. 56). Homens e mulheres compram juntos bens de consumo duráveis, enquanto as compras do consumo do dia-a-dia são ainda primordialmente tarefas femininas. $\mathrm{O}$ tempo gasto com cuidados pessoais são notavelmente iguais entre os dois sexos (p. 58); esta categoria inclui serviços pessoais, dormir e descansar, e fazer as refeições. Contudo, se tivermos em mente as responsabilidades das mulheres de cozinhar e cuidar das crianças, fica bem claro que o tempo de refeição possui conotações diferentes para os homens e para as mulheres - por exemplo, homens são usualmente servidos à mesa. Até o ato de dormir pode não ser igualmente considerado: a uniformidade no horário de ir para a cama e de acordar nem sempre significa a mesma quantidade de horas de sono, especialmente quando há crianças pequenas ou pessoas de idade na família, ou se alguém está doente. 


\section{O ‘HOMEM-ECONÔMICO’ DE BECKER}

Becker $(1960,1981,1987)$ fornece uma tentativa sistemática para lidar com a economia da família. Ele define a família como uma firma, com o tempo disponível aos seus membros sendo alocado de acordo com a maximização da utilidade marginal (neste caso, coletiva) condicionada às restrições de tempo e renda, seguindo a teoria neoclássica tradicional.

Os dados apresentados na seção anterior não confirmam a hipótese de Becker de que trabalho doméstico e trabalho assalariado são sistematicamente substitutos um do outro. Como vimos, para as mulheres, esses dois tipos de trabalho são geralmente somados e não substitutos. Mesmo a troca entre máquinas e trabalho doméstico não acontece da forma esperada pela teoria neoclássica, que propõe uma substituição marginal baseada no custo de oportunidade do tempo gasto, por meio da qual quanto mais mulheres são pagas pelo seu trabalho, mais elas supostamente substituiriam trabalho doméstico por máquinas. Ao contrário, a introdução da tecnologia no trabalho doméstico depende de padrões sociais de consumo, que por sua vez são determinados por hábitos, gostos e contextos culturais. Dadas as coordenadas sociais, 'donas de casa' e 'mulheres assalariadas' usam os mesmos eletrodomésticos e os mesmos serviços.

A visão da família como uma firma também não pode ser justificada em termos da maximização coletiva da utilidade dadas certas restrições. Como no caso das máquinas, a permutabilidade entre o trabalho assalariado da mulher e o trabalho doméstico do homem depende muito mais de fatores culturais do que dos salários relativos. $\mathrm{Na}$ verdade, entre homens e mulheres não há troca das responsabilidades domésticas (além daquelas dadas pelas convenções sociais) mesmo quando o salário da mulher é mais alto do que de seu parceiro. Assim, o que é realmente importante na determinação da relação entre trabalho doméstico e assalariado é o contexto das normas sociais, hábitos, gostos, relações de poder, etc. O modelo de Becker não diz nada sobre esses fatores, uma vez que ele reduz a análise ao problema da alocação de recursos escassos tendendo ao equilíbrio e, logo, à estática. Ademais, as condições lógicas do modelo 
são tais que as variações de preços e quantidades (salários e tempo de trabalho) não são capazes de afetar os parâmetros da função. Na realidade, os próprios parâmetros são precisamente os elementos mais importantes da análise, uma vez que eles refletem a estrutura fundamental do mercado de trabalho e por serem afetados por mudanças nos preços e quantidades.

As relações básicas entre modos de produção e modos de reprodução social não podem ser reduzidas à distinção entre parâmetros históricos gerais e funções a-históricas de preço-quantidade. A forma como a quantidade é medida em função do preço sempre depende de estruturas sociais e relações de poder que mudam no tempo e espaço (isso foi provado com a crítica da teoria do capital neoclássica). Além disso, no que diz respeito aos mecanismos de ajustamento do mercado de trabalho, a flexibilidade do sistema não depende da elasticidade dos salários, mas da natureza flexível historicamente dada de instituições como a família. O que precisamos reconhecer, portanto, é uma flexibilidade institucional, e não uma suposta elasticidade das funções preço-quantidade.

Algumas das observações de Becker são até razoáveis, e já tinham sido brilhantemente expressas por Adam Smith: por exemplo, o fato de que a estrutura da família é afetada por fatores econômicos (dentre outros) que determinam as relações entre os sexos e o número de crianças. $\mathrm{O}$ que não se pode aceitar em Becker são os instrumentos e a abordagem metodológica usadas para expressar esses aspectos da realidade. A caracterização da família como uma firma acentua os piores defeitos do reducionismo neoclássico. $\mathrm{O}$ uso do tempo, relações entre os sexos, e a decisão de ter ou não filhos, são vistos como sistematicamente dependentes do nível de salário, e de uma forma tão determinística que se tornam, além de repugnantes do ponto de vista ético, inúteis do ponto de vista analítico.

Willis (1987), na sua pesquisa da 'Economia da Família', demonstra para onde os cálculos intertemporais da utilidade podem levar os economistas. Podemos chamar isto de "Modelo da Dinastia de Investimento Ótimo em Crianças":

As preferências parentais podem ser representadas dentro do arcabouço de sobreposição de gerações com uma 
'função de utilidade dinástica' se a função utilidade dos pais é igual à soma das suas próprias utilidades com consumo e da utilidade vitalícia de cada um dos filhos, multiplicada por um peso representando o grau do altruísmo parental. Devido à recursividade, a função utilidade dos pais é igual à soma dos níveis de utilidade do consumo próprio dos filhos, netos, e todas as gerações subsequentes na dinastia, descontada pela taxa de altruísmo. Dadas as preferências, o nível de utilidade vitalícia de uma criança (i.e. a soma ponderada da sua utilidade com consumo e a utilidade de seus filhos) pode ser interpretada como uma medida escalar da qualidade da criança ${ }^{14}$.

Seguindo essa estratégia, Becker e Nigel Tomes (...) abordam a determinação do nível de investimento ótimo em crianças. A análise nos dá um modelo explícito do papel da família no financiamento do capital humano (Willis, 1987, p. 75)

A economia neoclássica é geralmente baseada na negação da natureza específica do trabalho como uma mercadoria - e em particular da especificidade do processo de reprodução e suas implicações políticas. Sua teoria de salários é baseada na velha teoria do fundo de salários, que coloca que os salários serão determinados de acordo com a oferta e demanda, determinadas a partir da relação sistemática entre o tamanho da população e uma quantidade de capital. Primeiro, a teoria dos salários como custos da reprodução social foi rejeitada, removendo então o foco do processo de reprodução do trabalho; então, segue com a determinação simultânea dos salários e do preço relativo de outras mercadorias, rejeitando a teoria exógena da distribuição. Nesse contexto, se a reprodução do trabalho é reintroduzida na análise econômica, um esforço desesperado precisa ser feito para reconciliar esses problemas com o método analítico redutivo. Logo, não é acidental que Becker, precisamente quando fala sobre problemas da reprodução, reforça a a-historicidade da análise neoclássica. A sua teoria tem sido usada para explicar a reprodução de todos os grupos

${ }^{14}$ N. T. Willis (1987) explica em seu texto que "qualidade da criança" segue o conceito de Becker (1960), medida pelo nível de gasto por criança, de acordo com preferências parentais. 
sociais hoje existentes ou que já existiram no mundo. Todo indivíduo irá racionalizar suas escolhas por meio da maximização da utilidade marginal tanto quanto ele/ela conseguir; o importante é que cada escolha possa ser representada em um diagrama de curvas de indiferença sujeitas à restrição de uma quantidade dada de recursos.

Finalmente, mas não menos importante, as medidas da enorme contribuição das mulheres às economias nacionais com seu trabalho doméstico, calculada entre 30\% a 40\% do Produto Nacional dependendo do método utilizado (Goldschmidt-Clermont, 1982), demonstram o caráter irreal da teoria dos salários como função da produtividade do trabalho, usada por economistas neoclássicos.

\section{UM SALÁRIO POR DOIS TRABALHOS}

A experiência do duplo trabalho das mulheres nos força a olhar novamente para a dicotomia entre a família e o mercado, não somente em conexão com a força de trabalho feminina, mas também para uma análise mais geral do mercado de trabalho.

A complexidade da dupla carga das mulheres vem da constante necessidade de mediar conflitos profundos, bem como tensões mais superficiais. Os conflitos profundos são conectados com a histórica disparidade de poder entre os sexos - expressa como controle sobre o trabalho reprodutivo da mulher - e a contradição crucial no sistema social entre os processos de reprodução de pessoas e o processo de acumulação de capital. As contradições mais superficiais são aquelas envolvendo os conflitos contínuos e muitas vezes dilacerantes que nascem da separação entre os tempos e os espaços dos dois processos. A identidade da mulher, e seu sucesso em conseguir não somente se encaixar num molde fixo da família e da sociedade, mas também em escapar dele, dependem da sua capacidade de agir dentro dessas relações conflituosas (Balbo, 1987). As mulheres são, na verdade, muito dinâmicas e criativas para encontrar maneiras de mudar as condições de suas vidas, mas elas enfrentam obstáculos estruturais que limitam a sua margem de manobra. 
A 'dupla jornada' das mulheres coloca-as em uma posição ideal para expor o artifício pelo qual dois trabalhos são feitos por um salário. Em essência, isso se mantém igual no contexto tradicional do homem 'ganha-pão' e da mulher 'dona de casa', no mais moderno onde ambos são 'ganha-pão', ou no pós-moderno onde o homem eventualmente divide as tarefas domésticas. A natureza desse artifício capitalista pode ser exposta somente com uma mudança radical da perspectiva analítica (e política).

A desconfortável relação entre a troca de poder de trabalho da mulher no mercado e a organização diária do processo de reprodução é amplamente refletido nos dados sobre emprego feminino. Os dados revelam que, assim como há um núcleo de trabalho doméstico para as mulheres assalariadas, também há um núcleo sólido de mulheres que estão impossibilitadas ou indisponíveis para entrar no mercado de trabalho assalariado, pelo menos durante alguns períodos de suas vidas. Deve-se ressaltar que algumas mulheres combinam trabalho doméstico e outros trabalhos em casa - como artesanato, manutenção de um comércio e agricultura. Essas mulheres formam uma categoria adjacente das 'donas de casa' porque elas realizam trabalho - na maioria das vezes não-remunerado - dentro da família, mas elas são contadas como empregadas nas estatísticas. Elas não são um grupo marginal; o seu trabalho, precisamente porque é realizado em uma unidade de produção definida pela família, envolve uma contínua interação entre trabalho para o mercado e trabalho reprodutivo: na realidade, essas mulheres normalmente entram nesses trabalhos pelo casamento (Finch, 1983).

Em termos de horas de trabalho, a influência do trabalho doméstico no trabalho assalariado torna-se ainda mais óbvia. No nível internacional, o trabalho meio-período émajoritariamente um fenômeno feminino (Beechey \& Perkins, 1987; Walby, 1990). Outros sistemas de gerenciamento de tempo (turnos, trabalhos noturnos, horário flexível, horas extras, plantões) são usados de forma diferente por homens e mulheres; e a disparidade é novamente baseada nas diferentes responsabilidades com a família. As mulheres são preparadas para trabalhar em vários horários do dia, mas elas resistem fortemente a cronogramas indefinidos e imprevisíveis. A grande variedade de soluções dá aos empregadores uma força de trabalho 
que é geralmente flexível, ainda que mais rígida para alguns empregados. As horas de trabalho escolhidas pelas mulheres, incluindo aquelas mais desfavorecidas, são fortemente determinadas pelas necessidades da família - um elemento que tem pouca importância para os homens.

$\mathrm{O}$ aumento dos índices de emprego das mulheres não pode ser lido como um progresso contínuo para um místico 'trabalhador neutro', definido por uma igualdade imaginária. O sentimento de frustração que as mulheres experimentam demonstra a insuficiência das soluções oferecidas pelo sistema atual para os problemas envolvidos na relação entre produção e reprodução social, que não são de forma alguma limitados às mulheres. Usando a experiência das mulheres em ambos os processos, nós podemos começar a nos distanciar de uma perspectiva sacrificial (inculcada nas mulheres de vários níveis ideológicos e simbólicos, e não somente pela direita política) para uma baseada em uma crítica social e política do trabalho assalariado capitalista.

Nesse ponto, as 'donas de casa' não são mais passivas e inertes do que as mulheres assalariadas; elas são somente menos notadas pelas ideologias em torno do trabalho. Há duas formas de tornarem-nas invisíveis: uma é considerá-las como potenciais sujeitos políticos só caso se tornem assalariadas, e a outra é glorificar o seu papel e retirá-lo da esfera econômica e política. Ambas as perspectivas têm o objetivo de neutralizar o trabalho doméstico como uma questão para negociações políticas.

\section{PERSPECTIVAS POLÍTICAS}

A consciência das dimensões qualitativas e quantitativas do trabalho reprodutivo e sua localização adequada no quadro analítico geral têm implicações cruciais para as estratégias das mulheres. Se a política diz respeito apenas ao trabalho assalariado, as mulheres estão presas no dilema da proteção-igualdade. Ou seja, ou devem esconder o seu trabalho reprodutivo para serem iguais aos homens no local de trabalho, ou o reconhecem e pedem "proteção" por isso. Mas, uma vez que a relação histórica entre produção e reprodução é explicitada, o vínculo funcional entre trabalho assalariado e trabalho doméstico torna-se uma questão geral 
e não uma questão da mulher. A "proteção" é exposta como uma pequena manobra, a "igualdade" como uma miragem; e ambas as estratégias são extremamente inadequadas para lidar com os problemas derivados do conflito da relação entre produção e reprodução sob o capitalismo. As mulheres percebem isso claramente, mas são forçadas a aceitar medidas "protetoras", como empregos de tempo parcial, que prejudicam seus salários e carreiras, ou então brincar de tornar-se Mulher Maravilha para perseguir uma igualdade espúria no mercado de trabalho assalariado. Os salários escondem não só a dupla jornada, mas, de forma mais insidiosa, escondem a enorme quantidade de energia gasta pelas mulheres e que é absorvida por seus colegas homens para lidar com seus próprios problemas.

Nas circunstâncias atuais, a ideia de uma distribuição mais igualitária do trabalho reprodutivo entre homens e mulheres parece mais uma ilusão do que uma perspectiva real. Em primeiro lugar, o chauvinismo, historicamente sedimentado, tão persistente e generalizado que não há como ignorar, interage com a estrutura do mercado de trabalho. Em segundo lugar, os homens são conscientes o bastante de suas próprias lutas históricas por maiores salários reais e por menos trabalho, e não aceitariam um incremento da jornada de trabalho sem nenhuma compensação além da diminuição de seu sentimento de culpa. Uma redistribuição do trabalho doméstico será possível somente por uma redistribuição massiva de recursos a favor da reprodução da população trabalhadora. Essa redistribuição pode assumir diferentes tipos de "salários para trabalho doméstico" - benefícios monetários, licença remunerada, redução da jornada de trabalho com manutenção de salário, serviços públicos, etc. - e certamente favorecerá tanto homens como mulheres - mas, em qualquer caso, deve ser massiva e deve modificar os modos de produção.

Nas últimas décadas, a situação do mercado de trabalho, para as mulheres, se modificou extraordinariamente. As mulheres têm tido cada vez menos filhos e uma parte crescente de suas vidas deixou de ser regulada pelo ciclo biológico. Assim, elas podem permanecer por mais tempo num trabalho remunerado e, como já vimos, isso não significa necessariamente que farão menos trabalho doméstico. Com o aumento do 
cuidado de pessoas idosas e doentes, aumento do tempo gasto em viagens e compras, compromissos burocráticos, crianças que permanecem mais tempo em casa, homens com menos segurança no emprego, com trabalhos flexibilizados e estressantes, etc., as mulheres têm pouca esperança em uma redução da "jornada de trabalho total".

Os salários das mulheres se tornaram essenciais na composição da renda familiar, e temos diferentes modalidades de arranjos familiares. Mas isso não altera a relação entre produção e custos de reprodução do trabalho assalariado: isso significa apenas que o salário do homem não é mais suficiente para manter o patamar histórico do padrão de vida familiar. A relação entre salário dos homens e salário das mulheres e o padrão de vida real ainda é mediada por essa forma separada de organização da reprodução e pela necessidade de manter seus custos baixos o suficiente para permitir a formação e acumulação de lucros. Para esse propósito o trabalho doméstico ainda desempenha muito bem sua tarefa.

A evidência empírica parece mostrar que as mulheres não consomem mais com o propósito de trabalhar menos; ao contrário, elas trabalham mais para consumir mais. $\mathrm{O}$ fenômeno encontra semelhança ao das transformações que ocorreram na economia das famílias no século XVIII, quando os agricultores (independentes) foram induzidos de várias formas a depender do comércio de mercadorias e do mercado de trabalho para sua subsistência.

As mulheres geralmente usam o mercado de trabalho para escapar das formas de dependência pessoal inerentes às relações patriarcais: mas acabam com uma carga de trabalho maior e geralmente não conseguem escapar da armadilha de baixos salários e pobreza. $\mathrm{Na}$ verdade, acontece que, por um lado, ganham alguma liberdade pessoal por meio da redução das imposições pessoais que restringem sua liberdade de ação, e, por outro lado, as mulheres estão mais pressionadas a vender sua força de trabalho no mercado de trabalho devido a um aumento histórico generalizado da insegurança do acesso dos trabalhadores aos meios de subsistência ${ }^{15}$.

\footnotetext{
${ }^{15}$ Sen distingue entre liberdades negativas - em relação aos impedimentos à liberdade de ação - e liberdades positivas refletindo as condições básicas de segurança. Ele define o padrão de vida não apenas em termos de bens e serviços, mas também em termos de direitos, isto é, da
} 
Tudo isso só pode ser entendido se analisarmos a natureza do mercado de trabalho, que é aparentemente democrático (porque pressupõe livre escolha por parte dos trabalhadores), mas cujos traços subjacentes levam a uma insegurança tão profunda e disseminada que ameaça a liberdade individual. Ao expor a natureza do mercado de trabalho, em que se baseia o mercado de bens e serviços, a relação entre produção e reprodução, que caracteriza a economia capitalista, fica mais perceptível.

Para as mulheres, essa clareza é essencial porque ela traz o fato de que sua entrada no mercado de trabalho assalariado, ao mesmo tempo que, sem dúvida, resolve muitos problemas em suas vidas, não pode realmente "libertá-las". Na realidade, nem traz a libertação do patriarcado, porque o mercado de trabalho assalariado, como vimos, baseia-se exatamente nesta particular divisão sexual do trabalho na reprodução.

\section{MULHERES E ESTADO}

O trabalho doméstico é a base para uma certa relação entre as mulheres e o Estado. $O$ Estado é a instituição que regula o arranjo entre o processo de acumulação e o processo de reprodução social, como vimos nos capítulos três e quatro ${ }^{16}$. Os Estados modernos têm o papel de controlar os conflitos que emergem do trabalho assalariado e da particular divisão do trabalho e de recursos dele decorrente. Sob o capitalismo, o trabalho reprodutivo assume a forma de trabalho doméstico não remunerado, cuja função é reproduzir a população, especialmente os trabalhadores assalariados. Este arranjo permite que o sistema conte com a continuidade dos processos de produção e reprodução, sob a forma de comando social proporcionada pela insegurança endêmica dos salários. Uma relação proporcional e adequada entre os dois processos é a condição da qual depende a continuidade do processo de acumulação capitalista. Como vimos, essa proporção constitui o cerne da Economia Política.

possibilidade de fazer pleno uso da própria vida (Sen, 1987).

${ }^{16}$ N.T.: A autora se refere aos capítulos três e quatro do livro desta tradução, "Social Reprodution: the political economy of the labour Market". 
A insegurança da reprodução, inerente ao sistema salarial, induziu o Estado a assumir certas responsabilidades diretas para grupos sociais, como os trabalhadores com baixa remuneração, os desempregados, os trabalhadores sem remuneração e as pessoas sem remuneração que não tem de quem depender. O Estado, no entanto, nunca foi uma instituição neutra em relação às classes sociais; e muito menos seria assim em relação à questão de gênero e da divisão de trabalho no processo de reprodução. O controle sobre o trabalho das mulheres leva ao controle de toda a reprodução da população.

O Estado, de fato, está longe de ser passivo em relação ao controle das funções reprodutivas das mulheres, tanto em termos de quantidade como de qualidade. Por exemplo, sempre exercendo controle sobre o aborto - repressivamente ou permissivamente, de acordo com a necessidade (Walby, 1990). Também controlando a execução do contrato de casamento, que impõe obrigações domésticas e sexuais precisas às mulheres (Pateman, 1988). Além disso, tolerou como normal um certo grau de violência privada contra as mulheres, o que explica, em parte, a generalizada relutância para aprovar leis que proíbam a violência dentro da família; embora essa tolerância pareça contradizer as políticas de igualdade de direitos para todos os cidadãos, ela é bastante eficiente no controle do trabalho feminino e do corpo da mulher. O Estado também tolera o fato de que, em comparação com homens, as mulheres trabalhem mais, sejam mais pobres e tenham menos proteção em termos de seguridade social (Brocas, et. al., 1990).

Quando o Estado assume responsabilidades diretas em relação à reprodução, nunca pretende substituir o trabalho doméstico, mas apenas complementá-lo. As obrigações domésticas da mulher são sempre tacitamente aceitas na formulação de políticas sociais. Os serviços de saúde e as escolas não poderiam funcionar se não fossem sustentados por muito trabalho doméstico dentro da família. O viés é ainda mais evidente na prestação de serviços de enfermagem, creches e educação infantil. É sempre dado por certo, de forma implícita ou explícita, que os lugares serão alocados aos filhos das mães empregadas, reforçando assim a responsabilidade específica das mães, ao invés de reconhecer a 
responsabilidade pública social pelas crianças. A alocação de recursos públicos em vários níveis institucionais baseia-se sempre no princípio de que é basicamente responsabilidade da mãe resolver problemas relacionados às crianças. Assume-se geralmente que o trabalho e a energia das mulheres são ilimitados e não impõem restrições à política social.

Deve notar-se que mesmo quando há taxas elevadas de emprego feminino e universalidade de serviços públicos, como nos países escandinavos, os problemas da relação das mulheres com o Estado, que concernem ao trabalho reprodutivo, não foram de modo algum resolvidos. Precisamente porque esses países são tão avançados, eles mostram claramente o quão difícil é superar a ideia de que as mulheres são o principal instrumento de reprodução social - na família, no mercado de trabalho e nas instituições públicas (Hernes, 1987). Somente a resistência generalizada das mulheres em todos os níveis, incluindo níveis institucionais, pode expor os custos que as mulheres são obrigadas a suportar, em termos de trabalho e estresse, porque as responsabilidades de reprodução são lançadas sobre elas pelos homens e pelo Estado.

É sobretudo com o Estado que as mulheres têm que negociar as condições de seu trabalho reprodutivo. Elas não podem ganhar negociando em particular num mercado de trabalho que ignora o trabalho de reprodução das mulheres, a fim de pagar salários baixos tanto para mulheres como para homens. Além disso, em quase todos os países o Estado tornou-se o maior empregador de mulheres, portanto, uma luta bem-sucedida para modificar convenções e relações de poder no setor público também poderia servir como padrão para o setor privado.

Apenas a negociação direta com o Estado sobre os modos de reprodução pode corrigir, pelo menos em parte, os abusos de um sistema de produção que subordina a reprodução social à acumulação de capital. A divisão do trabalho reprodutivo entre os sexos está muito profundamente enraizada na estrutura do sistema social para ser transformada por uma simples racionalização dos tempos de trabalho individuais. A negociação das mulheres com o Estado, no entanto, não elimina a necessidade de expor e agir sobre o conflito profundo e historicamente estabelecido entre homens e mulheres na área de reprodução. A base material moderna desses 
conflitos está enraizada no acesso desigual aos meios de subsistência e na desigualdade do trabalho reprodutivo, bem como no controle geral sobre os corpos e vidas das mulheres mantidos pelos homens através do paternalismo e/ou do assédio e da violência.

\section{UM SUJEITO POLÍTICO}

$\mathrm{Na}$ atual situação, mulheres têm se tornado um sujeito social com uma influência decisiva. Não é coincidência que uma nova fase de conflitos se abriu sobre os modos de reprodução históricos. O movimento feminista dos anos 1970 se focou diretamente na questão da reprodução: contracepção, aborto, sexualidade, família, trabalho doméstico, saúde, serviços e padrões de vida foram os assuntos mais vigorosamente debatidos (Rowbotham, 1990). Durante os anos 1980, as energias das mulheres foram sobretudo canalizadas para a criação e expansão de instrumentos culturais. Editoras, livrarias e jornais dirigidos por mulheres, estudos, conferências e centros culturais de mulheres contribuíram para inclusão das mulheres entre os protagonistas - como também suas questões - no centro dos debates culturais atuais. Naquela década as mulheres também estabeleceram e consolidaram relações com as instituições públicas: administrações públicas locais, sindicatos, mídia, etc. Elas também colocaram a atenção no fato de que nas instituições públicas a representatividade das mulheres ainda é escandalosamente desigual.

$\mathrm{O}$ ativismo político e cultural das mulheres ajudou a estabelecer a questão de sua liberação sexual um elemento central na dinâmica social contemporânea. Desde os primórdios do movimento feminista, a questão da liberação sexual se distinguiu e se contrapôs à questão da emancipação (compreendida como a entrada das mulheres no mundo dos homens e a supressão da diferença entre os sexos). A rejeição das mulheres a esse tipo de nivelamento determinou as bases para uma crítica radical das instituições sociais nas quais nós vivemos. Essas instituições são criticadas não somente porque impõem barreiras à entrada, mas porque também estão baseadas na subordinação da mulher e delas são inseparáveis. Tudo isso levou a um intenso debate sobre as fundações teóricas das Ciências Sociais, que são 
somente aparentemente neutras: na essência elas são baseadas puramente nos pontos de vista dos homens com relação ao mundo e às mulheres (Braidotti, 1991; Pateman, 1988). Mesmo nas Ciências Físicas, instituições e abordagens metodológicas foram questionadas por sua parcialidade das suas perspectivas de pesquisa (Donini, 1990; Fox Keller, 1985; Harding, 1986).

O fato de que as mulheres formam um sujeito político não significa que as mulheres são todas iguais ou que têm os mesmos interesses. Elas são profundamente divididas por diferenças de classe, nacionalidade e raças, assim como por suas próprias histórias individuais. É evidente que as interações sociais entre sujeitos com diferentes níveis de poder são muito complicadas. Mas, clareza na questão específica da reprodução pode facilitar novas alianças. Por exemplo, até décadas recentes, o trabalho doméstico era uma grande fonte de divisão entre as classes porque o trabalho doméstico remunerado era um setor empregatício ocupado totalmente por mulheres. Hoje é muito menos comum uma mulher comandar outra no trabalho doméstico por meio do assalariamento ${ }^{17}$; além disso, o trabalho doméstico entre diferentes classes sociais ficou nivelado em grande medida por várias razões como a difusão de normas sociais, de produtos e tecnologias, mídia, de serviços sociais e da urbanização.

Adotando uma abordagem analítica que foca diretamente na reprodução e nas suas condições históricas, nós também encontramos um denominador comum para o trabalho das mulheres em diferentes países e

${ }^{17} \mathrm{NT}$ : Infelizmente, e como reflexo da gigantesca desigualdade socioeconômica que assola o Brasil, o trabalho doméstico remunerado ainda é muito comum no país. De acordo com os dados da Pesquisa Nacional por Amostra de Domicílios (PNAD) do quarto trimestre de 2017, as mulheres, embora sejam maioria na população em idade ativa, representam apenas 43,7\% da população ocupada. Dessas mulheres com alguma ocupação, 14,6\% são empregadas domésticas (em torno de 6 milhões de mulheres). Destas, 71,6\% ainda não possuem registro de trabalho e, portanto, não podem contar com direitos trabalhistas como previdência, férias, licenças de saúde, seguro-desemprego, etc. Das mulheres trabalhadoras domésticas remuneradas, 30\% é empregada em mais de um domićlio. O salário médio de uma trabalhadora doméstica em 2017 no Brasil foi de $\mathrm{R} \$ 859,09$, ou seja, 38,8\% da média salarial de todos os trabalhadores $(\mathrm{R} \$ 2.214,70)$. Com essa diferença salarial pode-se compreender porque mulheres no Brasil ainda comandam o trabalho de outras mulheres no âmbito doméstico, dificultando a união das mulheres para a atuação como sujeitos políticos no país.

Temáticas, Campinas, 26, (52): 69-104, ago./dez. 2018 
em diferentes economias (como exemplo, países do norte e do hemisfério sul). A multiplicidade e a especificidade das relações entre produção e reprodução estão certamente refletidas nas diferenças radicais entre as mulheres de diferentes países. Mas, dado o devido reconhecimento dessas relações no nível político, é possível encorajar a construção de alianças e solidariedade com a potencialidade de superar, pelo menos em parte, os conflitos entre mulheres de diferentes localidades no sistema internacional de acumulação capitalista. Nessa área, organização de mulheres e intelectuais começaram a criar instrumentos efetivos para reavaliar, no nível internacional, as relações historicamente dadas entre produção e reprodução em cada contexto real específico (Deere, 1976; Young, 1988; Brydon \& Chant, 1989). Instituições como DAWN ${ }^{18}$ (Development Alternatives with Women for a New Era), WID ${ }^{19}$ (Women in Development) e as reuniões de mulheres em várias organizações não-governamentais formam uma rede internacional para alternativas de políticas de desenvolvimento (Sen \& Grown, 1988).

\section{CONCLUSÕES}

$\mathrm{Na}$ minha análise do sistema capitalista, em paralelo à exploração do trabalho para a produção, eu explicitamente ressaltei a exploração do trabalho para a reprodução. Para analisar essa segunda forma de exploração nós devemos nos focar centralmente no trabalho de reprodução e no controle das mulheres para garantir a quantidade e a qualidade de trabalho necessário para a acumulação capitalista.

Para compreender a exploração de classe e a exploração de gênero é necessário reconhecer a relação funcional específica entre produção e reprodução. Isso não significa em absoluto que a organização política do conflito entre os sexos possa ser confinada dentro dos limites estritos dos sindicatos ou outras organizações históricas do movimento trabalhista. Essas organizações são tão patriarcais e chauvinistas que permitem pouco espaço para a necessária manifestação dos conflitos entre os sexos - na

\footnotetext{
${ }^{18}$ N.T. Sigla em inglês para Development Alternatives with Women for a New Era.

${ }^{19}$ Sigla em inglês para Women In Development.
} 
verdade, elas não estão nem abertas a uma crítica radical da exploração de classes. Elas tomam como garantido que as mulheres, com seu trabalho doméstico, absorverão as condições inseguras da reprodução que são endêmicas no trabalho assalariado. A impotência dos sindicatos afeta não somente as mulheres, mas também os homens - envolve não somente gênero, mas também classes. Eu tampouco imagino que o conflito entre os sexos é puramente um problema do capitalismo, ou da exploração do trabalho. O conflito está tão enraizado na história do desenvolvimento social, e tão disfarçado na história do pensamento social, que seria um absurdo imaginar que uma mera mudança nas perspectivas teóricas da Economia Política poderia rastrear suas fundações históricas e, sozinha, resolvê-las.

Com relação à questão do materialismo e do economicismo, eu acho que isso é simplesmente abordado em termos errados. A reprodução necessariamente tem um componente material. Ela está relacionada a corpos, nutrição, nascimento, etc. Mas, ao mesmo tempo, não há nada mais simbólico do que o corpo, o alimento, o nascimento e a maternidade. A diferença entre os sexos é, em primeiro lugar, biológica; mas sua percepção e expressão são profundamente arraigadas na estrutura da linguagem e nos mitos. Sua história pregressa é tão longínqua que os estudos atuais antropológicos sobre as mulheres praticamente só começaram a arranhar a superfície.

Minha abordagem para a Economia Política, no entanto, é claramente materialista, mas não necessariamente economicista. Eu não desejo que a Economia, como uma especificação do tema sob investigação - isto é, a produção, distribuição e a troca da riqueza -, seja confundida com economicismo, que tem muitas implicações reducionistas. Quando a devida atenção é dada ao processo de reprodução do trabalho, todo o conteúdo da Economia Política é necessariamente visto como inerentemente social e político. 


\section{REFERÊNCIAS BIBLIOGRÁFICAS:}

BALBO, L. Crazy Quilts: Rethinking the Welfare State Debate from a Woman's Point of View. In: Showstack Sasson, ed. Women and the State. London, Hutchinson, 1987.

BECKER, G. An Economic Analysis of Fertility. In: Demographic and Economic Change in Developed Countries. NBER, Princeton, Princeton University Press, 1960. . A Treatise on the Family. Cambridge, Harvard University Press, 1981. . Family. In: EATWELL, J.; MILGATE, M. \& NEWMAN, P., eds. The New Palgrave Dictionary of Political Economy. London, Macmillan, 1987.

BEECHEY, V. \& PERKINS, T. Women, Part-Time Work and the Labour Market. Cambridge, Polity Press, 1987.

BRAIDOT'TI, R. Patterns of Dissonance. Cambridge, Polity Press, 1991.

BROCAS, et. al. Women and Social Security, Geneva, ILO, 1990.

BRYDON, L. \& CHANT, S. Women in the Third World: Gender Issues in Rural and Urban Areas. Aldershot, Edward Elgar, 1989.

DALLA COSTA, M. \& JAMES, S., The Power of Women and the Subversion of the Community. Bristo, Falling Wall Press, 1972.

DEERE, C. D. Rural Women's Subsistence Production in the Capitalist Periphery. In Review of Radical Political Economy, vol. 8, pp. 9-17, 1976.

DONINI, E. La nube e il limite, donne, scienza, percorsi nel tempo. Turin, Rosenberg and Sellier, 1990.

EUROSTAT. Employment and Unemployment. Brussels, EEC, 1989.

FADIGA ZANATTA, A. L. Donne e lavoro. In: ISTAT, Associazione Italiana di Sociologia, Inmagini della Societa' Italiana, Rome, ISTAT, 1988. 
FEDERICI, S. Counterplanning from the Kitchen, Bristol, Falling Wall Press, 1976.

FINCH, J. Married to the Job: Wives' Incorporation in Men's Work. London, Allen e Unwin, 1983.

FINCH, J. \& GROVES, D. eds. A Labour of Love: Women Work and Caring. London, Allen and Unwin, 1983.

FLECK, L. On the crisis of Reality. In: Cohen and Schnelle, eds. Cognition and Fact, Boston, D. Reidel Publ, 1986.

FOLBRE, N., 'Exploitation Comes Home: a Critique of the Marxian Theory of Family Labour', In: Cambridge Journal of Economics, vol. 6, pp. 317-29, 1982.

FOX KELLER, E. Reflections on Gender and Science. New Haven, Yale University Press, 1985.

GERSHUNY, J. \& JONES, S. Time Use in Seven Countries. Dublin, European Foundation for the Improvement of Living and Working Conditions, 1986.

GOLDSCHMIDT-CLERMONT, L. Unpaid Work in the Household: a Review of Economic Evaluation Methods. In: Women, Work and Development Series, Geneva, ILO, 1982.

GRONAU, R. Leisure, Home Production and Work: the Theory of the Allocation of Time Revisited. In: Journal of Political Economy, vol. 85, p. 1099-123, 1977.

HAKIN, C. Job Segregation Trends in the 1970's, In: Department of Employment Gazette, vol. 89, pp. 521-9, 1981.

HARDING, S. The Science Question in Feminism. Ithaca, Cornell University Press, 1986.

HARTMAN, H. \& RESKIN, B. Women's Work, Men's Work. Sex Segregation on the Job. Washington, National Academy Press, 1986. 
HERNES, H. M., 'Women and the Welfare State: the Transition from Private to Public Dependence', In: Showstack Sassoon, ed. Women and the State, London, Hutchinson, 1987.

HIMMELWEIT, S., \& MOHUN, S. 'Domestic Labour and Capital' In: Cambridge Journal of Economics, vol. 1, pp. 15-31, 1977.

ISTAT. Indagine sulle struture e i comportamenti familiar. Rome, ISTAT, 1985.

JARDINE, N. The Fortunes of Enquiry, Oxford, Clarendon Press, 1986.

PAHL, R. L. Divisions of Labour, Oxford, Basil Blackwell, 1984.

MALOS, E., The Politics of Housework, London, Alison and Busby, 1982.

MAURIN, R. Types de pratique quotidiennes, types de journnées et determinants sociaux de la vie quotidienne. In: Economie et Statistique, No. 223, p. 41-61, 1989.

MOLINEAUX, M., 'Beyond the Housework Debate', In: New Left Review, vol. 116, pp. 3-27, 1979.

PATEMAN, C. The Sexual Contract. Cambridge, Polity Press, 1988.

ROBINSON, J. P. \& CONVERSE, P. C. Social Change Reflected in the Use of Time. In: A. Campbell and P.C. Converse, eds. The Human Meaning of Social Change. New York, Sage, 1972.

ROWBOTHAM, B. The Past is Before Us. Harmondsworth, Penguin, 1990. ROY, C. L'emploi du temps des mères et pères de famille nombreuse. In: Economie et statistique, vol. 142, p. 59-78, 1982.

. La Gestion du temps des hommes et des femmes, des actifs et des inactifs. In: Economie et statistique. Vol. 223, p. 5-40, 1989.

SARACENO, C. Division of Family Labour and Gender Identity. In: Showstack Sasson, ed. Women and the State. London, Hutchinson, 1987.

SEN, A. The Standard of Living. In: G. Hawthom, ed. The Tanner Lectures, Clare Hall College. Cambridge, Cambridge University Press, 1987. 
SEN, G. \& GROWN, C. Development, Crises and Alternative Visions. London, Earthscan Publication, 1988.

SZALAI, A. Women's Times. Women in the Light of Contemporary Time-Budget Research. In: Futures. October, vol. 7, p. 385-99, 1975.

VANECK, J. Time spent in Housework. In: A. H. Amsden, ed. The Economics of Women and Work, Harmondsworth, Penguin, 1980.

WALBY, S. Theorizing Patriarchy, Oxford, Basil Blackwell, 1990.

WILLIS, R. What Have We Learned from the Economics of the Family. In: American Economic Review, vol. 77, p. 68-81, 1987.

YOUNG, K. Women and Economic Development: Local, Regional and National Planning Strategies. Oxford, Unesco, 1988.

Artigo recebido em 12/04/2018 e aprovado em 08/08/2018. 
